\title{
Coastal cities and sustainability. Case study: San Juan roadway system
}

\author{
María Helena Luengo-Duque ${ }^{1}$ \\ ${ }^{1}$ University of Puerto Rico, Río Piedras Campus, Design Department \\ Av. Dr. José N. Gándara, San Juan, Puerto Rico 00931 \\ maria.luengo@upr.edu
}

\begin{abstract}
Climate change poses threats to urban infrastructure, quality of life, and entire urban systems. Cities have to be able to adapt to climate-induced changes. Coastal cities have even more handicaps because of natural geographic conditions that affect sea levels rise and severity and frequently windstorms. This article provides an understanding of the functioning of the roadway system on the coastal ecosystems, the ecological services, and the built environment. The main objectives are Leverage Hurricane Maria research investments to advance in the development of a more sustainable urban model and identify the potential of the road system as a global intervention in the territory and in the urban metabolism to achieve it.

As a study case, San Juan Roadway System is analyzed to understand its relation with the vulnerability indexes. The results of this product scientific knowledge are guidelines that can serve as a basis for the generation of public policies for roadway system planning in order to deal with natural hazards and advance to sustainable urban development. The research approach is that the roadway system has a decisive impact on urban metabolism processes and hence on disaster vulnerability.
\end{abstract}

Keywords: Urban metabolism, Roadway system, Urban planning, Sustainability.

(C) Copyright 2020 Authors - This is an Open Access article published under the Creative Commons Attribution License terms (http://creativecommons.org/licenses/by/3.0).

Unrestricted use, distribution, and reproduction in any medium are permitted, provided the original work is properly cited.

\section{Introduction}

Urbanization provides countries opportunities to improve the lives of people and enhance economic development in towns and cities. However, inadequately managed urban growth and development can worsen inequalities, exclusion, and vulnerability.

One of the problems of the growth of cities is the increase of residential suburbs lacking sources of employment and services, which generates that billions of people commute to and from work every workday. A simple literature search of international transportation studies reveals that average commute times vary between 40 and $80 \mathrm{~min}$, with publictransit taking longer than car commutes [1].

In San Juan, the road infrastructure played an essential role in urban development. In 1930 the population moved in collective transport, and the private vehicle was limited to high-income families. In 2015, there were 661 motor vehicles per 1000 inhabitants [2], making Puerto Rico one of the countries with the highest number of vehicles per person. This urban model led to the construction of an extensive road network that responds almost exclusively to travel by car.

Puerto Rico's urban systems are facing an increasing number of challenges. These include the impact of the urban system on the local environment and, more globally, on the climate itself, both of which constitute major policy issues. Nevertheless, it is possible to identify opportunities for a change of model-oriented towards sustainability.

The two following facts illustrate the possibilities that roads offer for a large-scale territory intervention:

- There are 16,691 miles of streets, highways, and bridges in Puerto Rico.

- 25-40 percent of the land within urban areas is in the public streets right of way [3]. 
Streets have been studied from different approaches as urban elements through which it is possible to achieve more sustainable cities, Jan Gehl stats that is time to reclaim the streets [4]. There are many studies on the street as a fundamental urban piece of sustainability and resilience. Two main trends can be identified in street studies: those that point to the reconfiguration of its characteristics in order to contribute to active life [5]-[7] and those that recognize it as a critical piece in the management of runoff [8]-[10].

These two streams of research pursue shared objectives in terms of improving environmental conditions and human health. The validity and importance of both criteria are indisputable for any urban environment. Moreover, in coastal cities, streets can contribute to lower stress levels caused by natural disasters and increase resilience.

In the general framework described, the main objective of this article is to present an approach to the coastal cities' risk management from the roadway system, recognizing the street as an axis of high dynamics of social and natural processes (urban metabolism).

\section{The roadway system and the urban metabolism of the city}

The concept of urban metabolism, conceived by (Wolman, 1965) can be defined as "the total sum of the technical and socio-economic processes that occur in cities, resulting in growth, energy production and waste disposal" [11] Recently studies on urban metabolism inspire a more crossdisciplinary engagement and provide a critical perspective on how the relations between social and natural processes produce the urban features [12], [13].

Therefore, the underlying rationale behind the urban metabolism concept is that the relationship between the environment and the urban system can be described by systematically recording all flows to and from the environment in physical terms [14].

While twentieth-century sociologists and anthropologies paid great attention to the study of the streets, there are a few research going on the role of the streets in the processes of urban metabolism beyond the analysis of flows and stock of materials [15]. Nevertheless, streets have a decisive role in the way that these processes occur.
The industrial revolution was made possible to break the laws that governed the natural processes of the organic city, in which the water was the chief rector of the urban configuration. Accessibility to fossil fuels replaced resource-efficient strategies and erased maps of the organic city's metabolism [16]. New construction materials allowed the building of infrastructures at much higher speeds than those possible with traditional materials, including road infrastructures, which affect landscape configuration and connectivity by introducing barriers that alter and diminish the diversity of biological structures [17]. The asphalt allowed the extension of the road network, and with the private vehicle access to a large percentage of the population, urban dispersion was facilitated.

The self-displacement of the people from the street because of the cars brought as a consequence a cut with conventional processes: runoff, orchard irrigations, and fountains supply was from that moment, beyond the common understanding. This alienation of the relationship between socio-cultural and natural processes generated a psychological distance that facilitated anti-ecological practices. Such an attitude distances people emotionally and intellectually from the recognition that the environment is the condition of the possibility of life itself. As Ingrid Leman point, "the etymological root of environment relate to that which surrounds, no merely in a geographical or geometrical sense, but rather, in terms of a milieu" [18].

Landscape architect Michael Hough emphasize that these conflicts and human attitudes towards nature have motivated by the conception of environment and natural resources as assets for increasing wealth and wellbeing. In his book Cities and Natural Processes, he searches for ways in which the city and nature come together to promote alternative values [19].

Streets articulate and give continuity to squares, parks, commercial, cultural, and service spaces, thus constituting a thread of the social spaces of the city, but, commonly, its urban design is more concerned with long-held function conventions than with biophysical process as determinants of urban form.

Example of this lack of understanding of the biophysical process is the traditional storm drainage systems use in the streets nowadays in most cities, the conventional method of keeping the city's paved 
surfaces free of water: "Yet the benefit of welldrained streets and civic spaces is paid for by the environmental costs of eroded streams, flooding and impairment of water quality in downstream watercourses, a condition that is akin to environmental degradation by design costs of eroded streams, flooding and impairment of water quality in downstream watercourses, a condition that is akin to environmental degradation by design" [19].

Streets, paved with concrete and tarmac, lead floodwaters downstream much faster, increasing flood heights and flows [8]. Every year catastrophic flooding devastates a community in some parts of the world. Coastal regions are prone to destruction at the historic levels of Hurricane Harvey, Hurricane Sandy, Hurricane Katrina, and Hurricane Maria. Lowlands near rivers and lakes are also vulnerable. Indeed, flooding can happen anywhere it rains.

In the last years, architects and civil engineers have developed promising technologies for flood control, for example, movable flood barrier, watergates, and sandbags. However, the history of hydraulic technology even began long before Archimedes (287-212 B.C). The ancient water technology used their knowledge to conservation of mass, energy, and momentum used in present-day hydraulic design before the development of these concepts [20]. Streets used to be one of the main elements to contribute to water management.

However, water management, although it is a fundamental issue, is not the only contribution that the street can provide to city' risk management. As a circulatory system present in all the urban structures, streets could be escape routes, channels for resources supply, barriers, and axes for risk management.

The non-recognition of the processes of urban metabolism in the planning of the road system has generated cuts in the biophysical matrix, reduction of ecosystems, reduction of natural barriers against disaster events, reduction of people's health and many other problems that need to be addressed.

\section{San Juan' hazards, lessons learnt after disasters}

San Juan, like other cities on the coastlines, is changing rapidly due to both anthropogenic and climatic stressors [21]. For example, large-scale floods and other disasters bring devastating shortterm impacts; extensive recovery and rebuilding; and long-lasting social, economic, and ecological disruption. Straightaway following the disaster event, communities, cope with a range of dilemmas that include direct effects (e.g., loss of life, housing, clean drinking water, and infrastructure) and changes in disease risks, crime, community cohesion, and political structures that may be less obvious. Indeed, the social, economic, technological and ecological foundation of a community may be upended entirely [22].

Hurricanes and flooding are the most common hazards in Puerto Rico, although earthquakes and tsunamis are also threats. Every year the alarms trig in Puerto Rico against some hydro-meteorological hazard, the effects vary in intensity, when endangering people's lives and the infrastructures become more evident, but there are other damages less visible and therefore no less important to attend.

Though hurricanes are a natural disturbance within the Caribbean [23], there is a rising concern that projected increases in the frequency of intense hurricanes. In September 2017, Puerto Rico experienced an extreme disturbance. Hurricane Irma was the first category four hurricanes on record to pass over the island, followed by the second category 5, Maria, two weeks later.

Anthropogenic actions increase the effects of the hurricanes on the environment in ways that are sometimes no easy to perceive, e.g., the instant input of massive litterfall amounts after a hurricane can trigger changes in physical and chemical environments within forests at both small and large temporal and spatial scales, resulting in the alteration of forest successional stage and development [24].

Maria hurricane left lessons that it is essential to recognize and consider to move towards a more sustainable urban model.

Some of the damages that occurred during and after the hurricane Maria in Puerto Rico is highlighted are shown below [25]:

- Maximum inundation levels of 3 to $5 \mathrm{ft}$. above ground level occurred along the coast of northeastern of the island.

- The combined destructive power of storm surge and wave action from Maria produced extensive damage to buildings, homes, and roads along the east and southeast coast. 
- Numerous trees were downed, splintered, and defoliated.

- River flooding was unprecedented in some areas, especially in the northern portion of the island.

- The La Plata River flooded the entire alluvial valley including the municipality of Toa Baja, where hundreds of families needed to be rescued from their rooftops.

- Maria knocked down 80 percent of Puerto Rico's utility poles and all transmission lines, resulting in the loss of power to mostly all of the island's 3.4 million residents.

- At the end of 2017, nearly half of Puerto Rico's residents were still without power, and by the end of January 2018, electricity had been restored to about $65 \%$ of the island.

- Many communities were cut off as a result of flooding and mudslides.

A few months after Hurricane Maria (march 4 and 5 2018) an extreme sea swell affected once again the northern coast of San Juan. The roads close to the coast served as canals for the entrance of water and sand affecting urban areas and putting inhabitants at risk.

The primary efforts of Puerto Rico Recovery Plan are geared toward repairs, as can be seen from the Puerto Rico recovery plan: "The Federal Highway Administration (FHWA) allocated a total of $\$ 72.5$ million in "quick release" Emergency Relief funds: an initial \$2.5 million after Hurricane Irma, another \$40 million immediately after Hurricane Maria, and an additional $\$ 30$ million in late November. These funds were explicitly allocated to begin the repair process of critical roadways and bridges across the Island" [26]. To prevent this investment from being lost in a new disaster it is essential to recognize the natural processes in order to redefine the urban model in ecological terms.

\section{Urban metabolism of San Juan}

San Juan, like many other cities in the world, has a linear metabolism, which is characterized by a constant throughput of resources, materials, products, and waste. This linear metabolism results in unsustainable city-regions [27].

Paulo Ferrao [28] point out about three main issues that affect the urban metabolism of the cities: Aspects of the city that are the result of its location, climate, geography, geology, and topography, among other factors, are locked in, unchangeable. These locked-in aspects define a border for urban metabolism. The second issue is elements crated to overcome the immutable elements of the urban context, at enormous cost and consequence, for example, highways, which requiring significant neighborhood disruption and reconfiguration. The third issue is the on-going challenge of providing services to the urban population. Due to the dynamic of the society as emigration, migration, aging, and other social and cultural trends, cities are more often challenged to meet the reliable delivery of essential services.

Urban sprawl and low-density development defined the Puerto Rican urban environment. Also significant per capita land consumption of exurban lands, and almost total reliance on the automobile for transportation. Principal consequences include traffic congestion, increase in energy consumption and costs for community services, reduction of open spaces and fragmentation of habitats, and pollution of waterways and air [29].

In San Juan, the urban train has a short route, the modal system is inefficient, and the stations have no facilities. Density districts as Bayamon are connected with San Juan by highways and by train, but the inhabitants prefer the private vehicle due to malfunctioning of the modal system, although the journey by urban train is 30 minutes and by car can reach 2 hours in peak hours.

As a consequence, the private vehicle is overused. In terms of risks, San Juan's streets were conceiving according to the displacement needs regardless of the environment.

In the city of San Juan, as well as in many other cities today, the street is conceive exclusively as a connecting element that must provide a moving surface to the car, and not as a threading element of the social and natural processes from which they could flow and be found in a harmonious way circumstances that currently collide and get in the way. The main objective of this research is to recognize the restorative potential of the urban metabolism of the streets to increase the sustainability of the city

\section{Methodology}

The methodology proposed is aimed at: 
1. Leverage Hurricane Maria research investments to advance in recognition of a more sustainable urban model.

2. Recognize the link among roadway system, urban metabolism, and disaster vulnerability as an opportunity to better understanding the urban process and its implication to urban planning.

3. Define the critical aspects that affect the resilience and sustainability of the road system.

The data available for this study included various scales, including an urban scale (San Juan), a regional scale (Basin of the Bay of San Juan), and a national scale (Puerto Rico). The most important data sources used referred to 2014-19, but in some cases, the absence of the most recent data led to the use of a set of previous data. The time frame of the investigation presented in this article covered a period of twenty months, from January 2018 to August 2019. The primary data sources used were as follows:

- National Oceanic and Atmospheric.

- Administration: Tropical Cyclone Climatology, 2018.

- CCCPR: Puerto Rico Climate Change Council, 2014.

- Department of Transportation and Public Works (DTPW): Puerto Rico Highway and Transportation Authority.

- Google Maps: Traffic estimator: Weekly Average Daily (IMD), and Annual Average Daily (IMDA) indices.

- FEMA: Flood Maps, 2018. Information about flooding is considering mandatory for the urban development of the island.

- Planning Board Puerto Rico: Planning regulation; Special Flood Hazard Areas Regulation; Public Space Infrastructure Regulation; Traffic control, and public use of local streets; Soil information; Vegetation, and GIS. Maps provided for this site allows understanding the interaction between different layers of information.

The data is used to analyze the link between road systems an urban metabolism. In this sense, this study is tracked the flows of specific elements of the urban metabolism in order to:

- Recognize the critical points in which road system affect the urban metabolism. For this, San Juan's road system characteristics are analyzed in relationship to the social and environmental outcomes to understand how both lifestyles define by the road system and environmental affections due to the road built intervention contribute to defining the urban metabolism of San Juan. More than quantitative data, the concern is on the way road system is conceived in terms of promoting or facilitate a particular type of life, as well as their contribution to the definition of the city's urban metabolism.

- Analyze the water and energy management of San Juan's road system. The aim is to recognize the relationship between these essential urban metabolism flows and the vulnerability of the city. The study of water and energy patrons and management is based on the data sources mentioned above.

- From the previous analysis define the San Juan urban road system criteria that could increase the resilience and cope with the vulnerability.

\section{1. San Juan road system and urban metabolism processes}

Coastal roads constitute a significant segment of national road networks in Puerto Rico that provides access to fishing, residential, and tourism resources. In Puerto Rico, approximately 40 percent are coastal roads. The paved roads as coastal ring roads in Puerto Rico are due to the patterns of the human settlements since the main cities and are located on the coast. Typically, the areas served in the region include:

- Cities and towns;

- Industrial centers;

- Airports and seaports;

- Fishing villages;

- Inland agricultural parcels;

- Inland and coastal residential communities;

- Hotels; and 
- Beaches;

In Puerto Rico, as in the rest of the Caribbean, coastal roads are a necessity of life.

The recognition of the critical points in which road systems affect urban metabolism is analyzed through the GIS data of San Juan territory, and it helps to specify how the affectation occurs and, therefore, to prioritize the measures that should be taken to cope with the problem. Figure 1 shows the road system of San Juan, and Figure 2 the risk map of San Juan. The map overlays help to recognize the critical points between road infrastructure and natural risk.

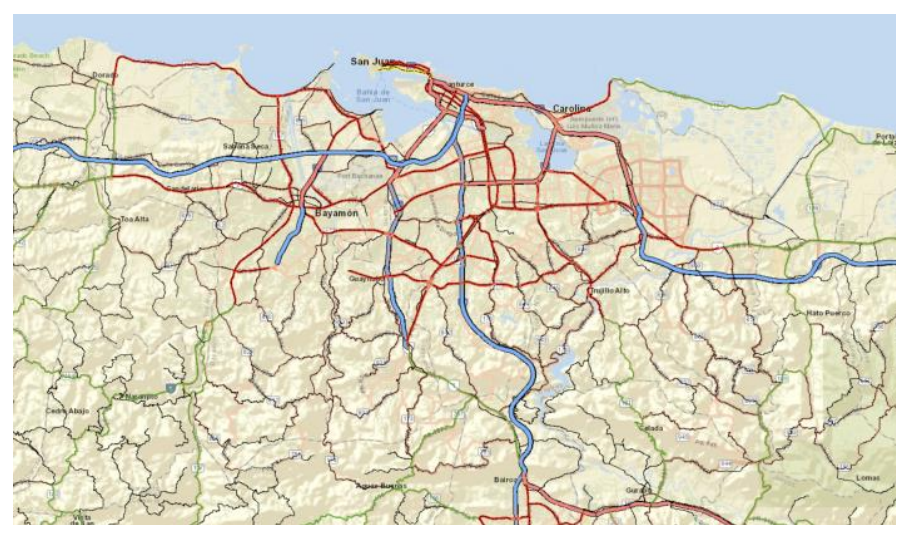

Figure 1. Road System of San Juan. Credit: Puerto Rico Planning Board [30].

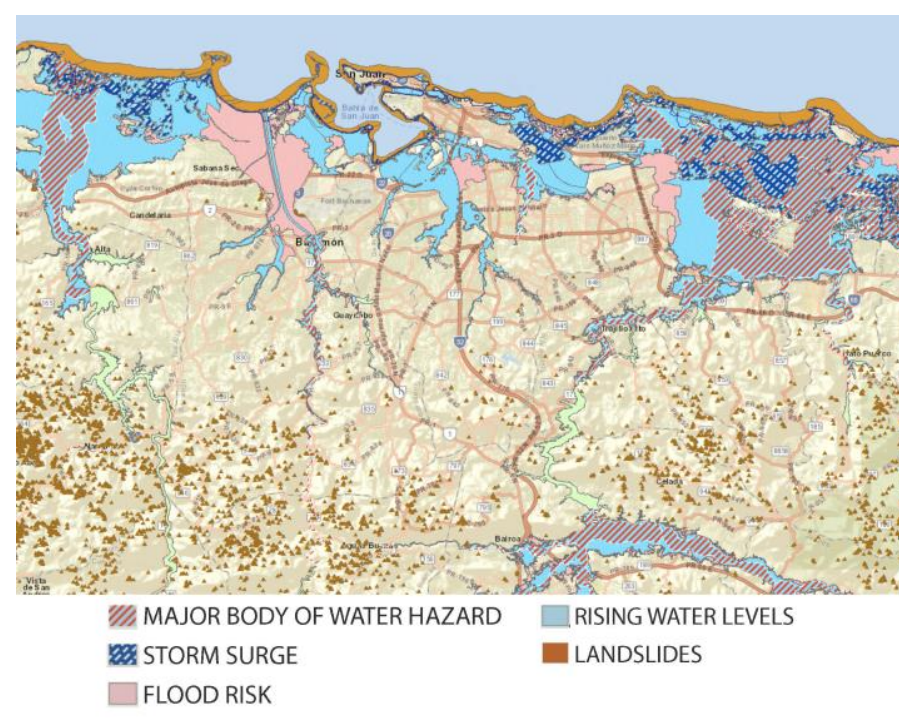

Figure 2. Risk Map of San Juan. Credit: Puerto Rico Planning Board [30].

The critical points where the road system affects the urban metabolism recognized through the analysis are:
- San Juan road system presents many natural hazards such as water hazard, storm surge, flood risk, rising water levels and landslide that endanger the population in several ways: possible escape routes from disasters are in danger of collapse, accessibility to goods and services may be blocked, and the city may be cut off from the rest of the island.

- $\quad$ Roads have replaced most of the watershed surface. When rainfall occurs, it can't infiltrate these impervious surfaces and will runoff directly into the stream very quickly. The result is a very fast and short-lived urban flood, rather than a gradual rise and fall in the river.

- The construction of coastal structures (such as breakwaters, groynes and seawalls needed for road construction) lead to changes in coastal sediment transport pathways, resulting in erosion in some areas and accretion in others. The removal of sediments from the coastal system (e.g., by dredging or sand mining), or a reduction in the supply of sediments (e.g., by the regulation of rivers) can also be associated with unintended erosion. Humaninduced climate change can modulate the likelihood and rate of coastal erosion [31].

- Flooding escalation and changes on runoff patron due to the loss of topsoil. As can be seen from the risk map above, the road system was built in high-risk areas, and worse, without considering the measures needed to address the geographical conditions of the site.

- The risk map shows how streets present a risk of being blocked, leaving the population without alternatives for escape or access to essential services in case of a natural disaster.

- The lack of alternative mobility and the disconnection between the different transport systems reduce the use of public transportation, which limits the capacity of people for selfmaintenance, restricts their activities and their contacts with other people, and as a consequence, the lifespan of any person.

- Due to the exclusively transportationoriented facilities of San Juan is reduced active travel, 
leading to physical inactivity and its disease consequences.

- The design of roads could help to ensure the relationship between the natural and social processes that characterize urban metabolism; however, the San Juan road system does not take into account the geographical qualities. The natural and social processes of the territory of San Juan are adversely affected, putting people at risk and increasing environmental problems.

\section{2. Urban metabolism of the street and materials construction}

The growing concerns about environmental health as well as rising fuel prices, automobile manufacturers are looking at ways to make driving more energy efficient. Nevertheless, road construction involves not only the energy required for construction and maintenance but also the embodied energy (the total sum of energy inputs for each process in the production chain). Embodied energy includes the extraction of raw materials, processing of these materials, transportation, disposal, and any other treatments that require energy. Units of energy measure embodied energy as a function of either material volume or density [32].

Beyond energy accounting, it is essential to consider the effects on natural capital, which include land, forests, fossil fuels, minerals, fisheries, and all other natural resources, regardless of whether or not they are exchanged on markets or owned. Besides, natural capital also consists of those ecosystems that provide valuable goods and services to the economy [33].

Road system construction requires reducing, transforming, and eliminating ecosystems. Ecosystem goods and services are essential for human wellbeing and cannot be substituted by economic capital. Ecosystems are also prone to irreversible conversion and abrupt collapse. Puerto Rico shows evidence of damages to its ecosystems due to anthropogenic actions such as reduction of reefs, erosion, soil acidification, mangroves reduction, and loss of biodiversity. In this case, the only satisfactory compensation rule for protecting the welfare of future generations is no other than protect and regenerate the essential ecological capital.
As the demands for higher inputs of materials and energy to sustain the growth of cities continue to increase, understanding the metabolism of cities becomes vital for policymakers and decision-makers. This research is trying to generate an alternative vision to seek solutions to cope with climate change and social inequities through the road system as elements of the urban space with high possibilities of transformation.

Each year, Puerto Rico's road network is affected because of floods and swells. In September 2017, Hurricane Maria struck Puerto Rico, devastating the island and cut off the communications between cities, towns, and communities after bridges collapsed and roads crumbling.

\section{3. Urban metabolism of the street and water management}

There is probably no intervention globally that has more impact on the surface and groundwater hydrology and landscapes than road construction. Roads obstruct the flow of water, channel runoff, and concentrate it, make it accelerate, and in the process trigger erosion and sedimentation [30]. Roads may rewrite the entire drainage pattern - causing waterlogging in one place and drying in others. However, in another way, road building has enormous potential, if done correctly, to help address climate resilience and water management.

Topography' features define the runoff; rivers also gain and lose water to the ground. Still, much of the water in rivers comes directly from runoff from the land surface, which is defined as surface runoff, and streets, as artificial channels, receive and change its natural trajectory.

The anthropic transformation of the territory has changed the runoff behavior. Additionally, climate change increases the threat of flooding from rising water bodies and rising sea levels. Figure 3 showing the San Juan Basin, as it can see, there is a vast expanse of wetlands and flood areas, and also is the highest density territory of the whole island of Puerto Rico. The island is affected by the risk of clime change and human settlement in low elevation coastal zones. This increase in development, population, and tourism has declined during the last several hundred years of the wetland resources. This reduction of wetlands could be related to the 
hurricane and cyclonic swells damage intensity [34][37].

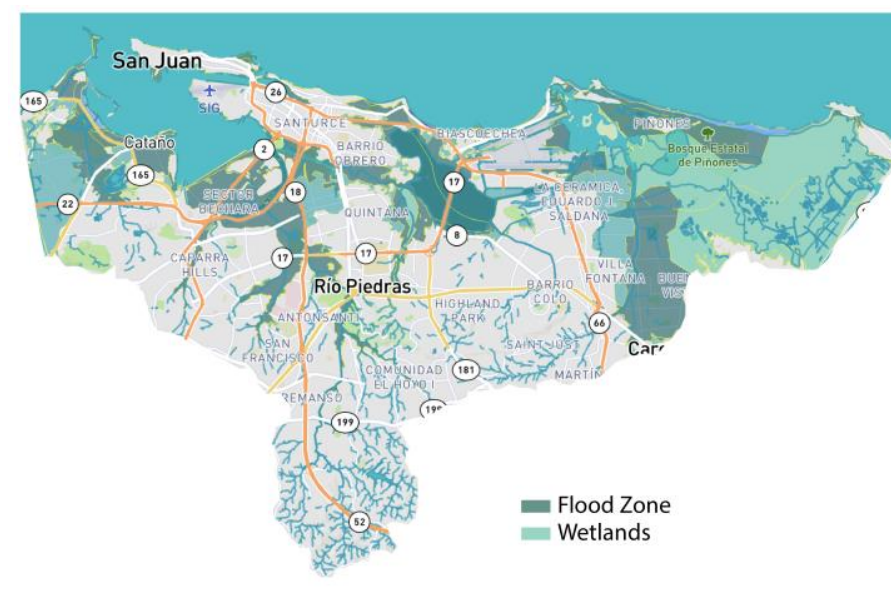

Figure 3. San Juan Basin. Credit: Study Program of the San Juan Basin [38].

Natural capital contributes to human welfare, both directly and indirectly, and therefore represents part of the total economic value of the planet. Ecological systems are valuable by itself independent of the human recognition, so the primary concern in San Juan must be the protection and recovery of wetlands in recognition of their value as natural capital, and this implies a public policy-oriented to redefine the urban environment in terms of landscape features. The roads, as a global intervention on the territory, have been responsible for a large percentage of wetland loss. When water runs through the roads without intention or control of direction or flow and finds receiving surfaces, it accumulates affecting urban dynamics. The potential of the roads could be used to organize runoff and define catchment or drainage areas.

\section{4. Urban metabolism of the street and energy use}

Even though, roadway construction generates a significant environmental impact, in terms of energy makes up a small part of the energy use of a roadway throughout its lifetime, the majority of which results from traffic on the roadway [15], [32].

Puerto Rico is one of the countries with the highest number of work-related trips in private vehicles [39]. The transportation sector is one of the largest sources of greenhouse gas (GHG) emissions in Puerto Rico, and these transportation emissions are dominated by on-road gasoline and diesel [40].

The analysis carried out in this research shows that the pre-eminence of the private vehicle is due to factors related to urban configuration, public space conditions, and the efficiency of public transport. In this sense, San Juan is characterized by urban sprawl model in which residential areas are separated from work and services. Streets do not generally present adequate conditions for alternative journeys (for pedestrians or cyclists), and public transport is rarely used due to the inefficiency of the service. These characteristics make the private vehicle be perceived as a first-order necessity.

The train consists of 16 stations operating on 10.7 miles $(17.2 \mathrm{~km})$ of track along a single line. Although its route is short, it travels through an essential part of the metro area in which many of San Juan's main activities are. Nevertheless, its stations and the surrounding environment do not have qualities that would encourage more sustainable lifestyles. Following is highlighting the most outstanding features of the transport system of San Juan:

1. Absence of bicycle paths.

2. Poor accessibility.

3. Traffic barriers.

4. Inefficient multimodal transport system.

5. Lack of public space.

6. Close to derelict sites.

7. Lack of urban furniture and lack of adequate conditions for transference areas.

8. Lack of pedestrian facilities at street intersections (ramps, accessible pedestrian push buttons, and signals, nonvisual cues).

Unused urban space close to train stations has increased crime and increased risk to public health and welfare. People use to avoid train stations and their surroundings due to insecurity. Gándara Park is one of the few urban green spaces in San Juan (Figure 4), but currently, this park is perceived as insecure because although it receives constant maintenance, it does not have activities that encourage its use and has been occupied by homeless and drug consumers. 


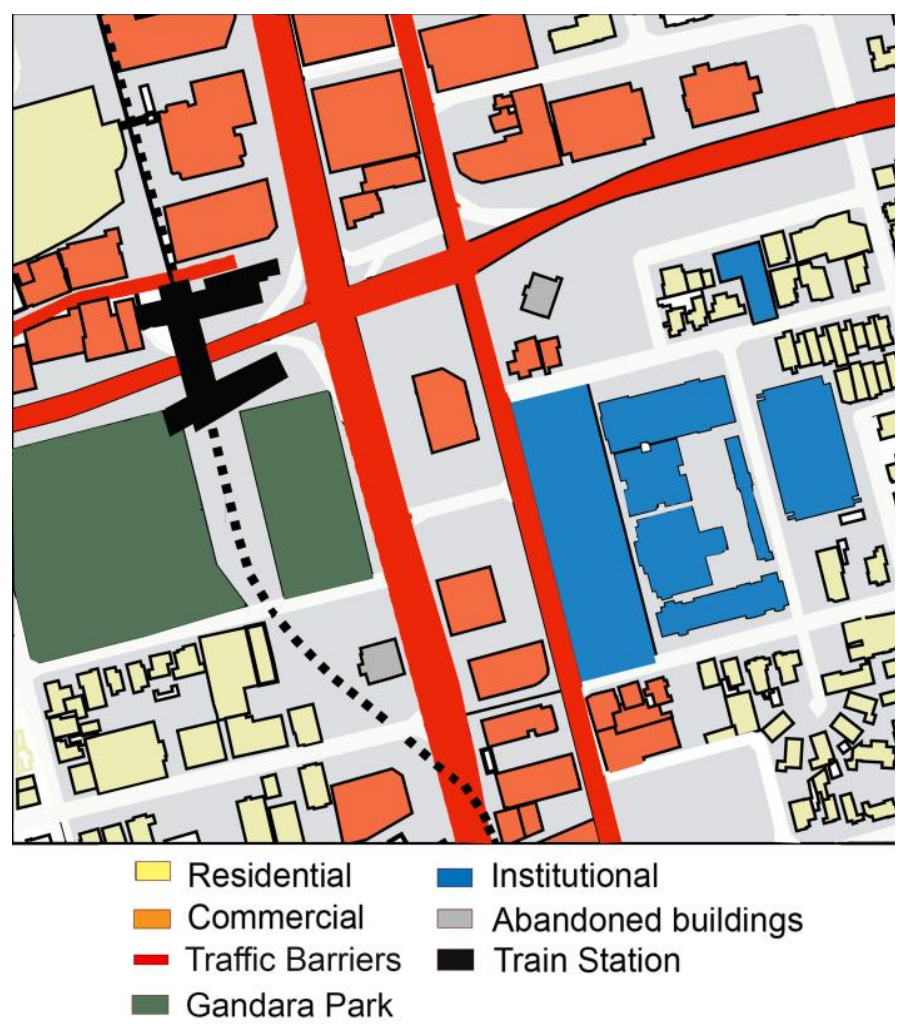

Figure 4. Roosevelt Train Station.

In Cupey Train Station (Figure 4), one of the exits leads to an abandoned site, and the streets surrounding are real traffic barriers without facilities to pedestrians. The isolation of the train station due to multichannel highways is a common feature in San Juan. Highways also divide neighborhoods and divided residential areas from service zones affecting the quality of life and generating inequity opportunities to the population.

In San Juan, pedestrians are forced to cross multi-lane highways. The city facing traffic-related problems: frequent congestion, air, and noise pollution, and although accident levels were not excessively high, there was a growing general perception of a lack of security. To the exception of the old San Juan, which, although it allows the entrance of vehicles it is friendly with the pedestrian, the rest of San Juan's streets and squares are designed to accommodate car traffic, which becoming unattractive. The form of the city affects energy consumption, and an inefficient mobility system generates impediments that increase the need for vehicle use and, therefore, the increase in energy consumption.

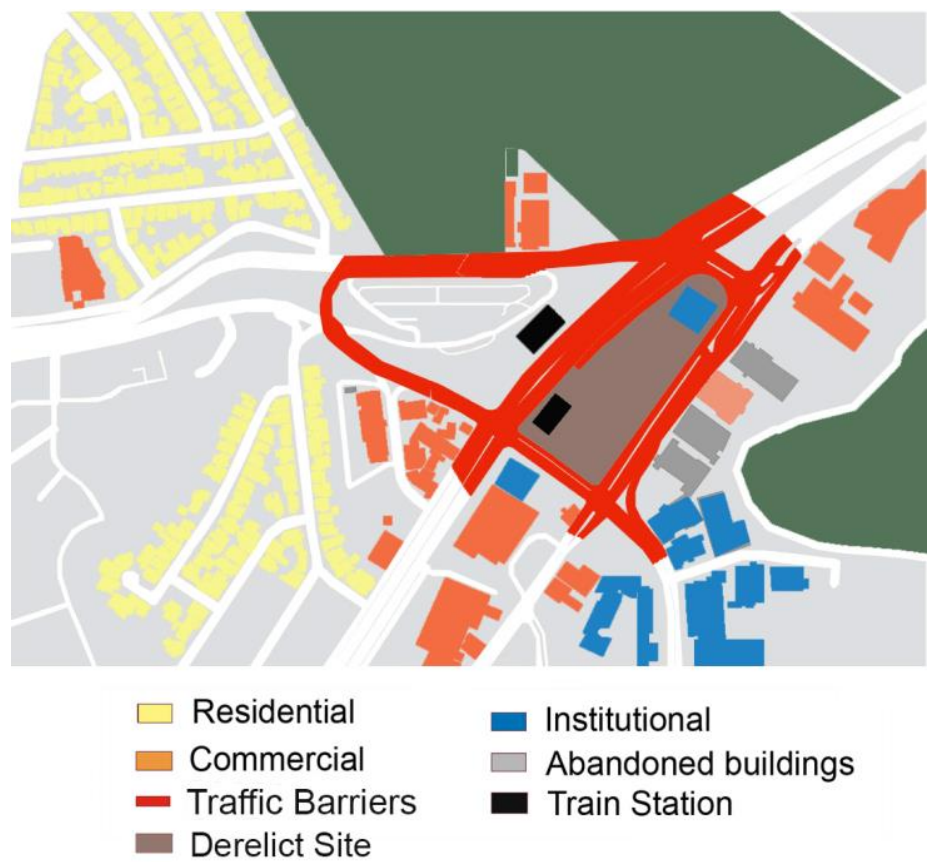

Figure 5. Cupey Train Station.

\section{5. Road system and natural risks}

Risks in the urban environment have many origins; they are generally recognized as caused by the interaction between society and natural systems (e.g., rainfall, floods, and cyclones). In terms of frequency and visibility, they can be classified into two types: Unexpected risks, which become visible quickly, such as floods or hurricanes, and last for a short period varying from hours to weeks, and continuous risks, very slow events that are barely perceptible by society, such as rising sea levels [41]. Every year Puerto Rico is subjected to natural events that affect urban dynamics. From 2000 to 2014 were recorded two hundred and thirty tropical storms, one hundred and eleven hurricanes, and forty-nine significant hurricanes in the Atlantic basin, many of which affected Puerto Rico in different ways [25]. In 2017 Hurricane Irma and Hurricane Maria left most of the population without essential services.

Climate change is expected to cause an accelerated rise in sea level with high flooding, more frequent flooding, accelerated erosion, increased water tables, more saltwater intrusion, increased cyclonic swells and frequent hurricanes [42].

Urban areas adjacent to the coast, such as San Juan city, experience both the influence of the discharge of rivers and the sea; the roads increase 
the vulnerability that this condition entails because of the changes in the landscape. Road construction results in the conversion of existing habitats to pavement and road verge. Road construction also results in the indirect destruction of surrounding habitat through the siltation of stream and drying of wetlands due to interrupted water flow. The loss of habitat to roads is far from inconsequential. The change of landscape composition affects natural barriers against hazards as hurricanes and floods. In Puerto Rico, the coastal lowlands, where mangroves occur, are today landscapes dominated by humans: urban developments, industries, pastures, agricultural/hayfields, and wetlands cover these lands [43]. Large expanses of mangroves have been removed for the construction of roads due to urban sprawl.

Mangroves are found on the front line in terms of their position relative to many coastal hazards. Mangroves often modify coastlines through their ability to attenuate waves, capture sediments and build soils and it is these same properties, which make them essential in terms of reducing hazard intensity on landward margins and of decreasing exposure. They also provide many associated benefits that can help reduce the vulnerability of coastal communities and support recovery following hazard impacts [31]. Problems related to climatic changes and natural hazards have to be recognized as inherent features of the environment in order to design cities capable of withstanding or recovering without so much hardship.

Three fundamental premises are derived from these arguments:

1. Threat situations in coastal cities occur periodically, and can, therefore, be predicted to some extent from the analysis of previous events.

2. Urban planners should recognize the different layers of information provided by the society-territory system, as well as their metabolic flows and natural risks.

3. The road system, as global mayor intervention on the territory, could contribute to reconfiguring the city model related to natural processes.

\section{Results and discussions}

The study of the San Juan road system identified the following characteristics related to social and environmental consequences expressed in the following table:

Table 1. The Road system of San Juan related to social and environmental outcomes.

\begin{tabular}{|c|c|}
\hline $\begin{array}{l}\text { Characteristics of } \\
\text { San Juan Road } \\
\text { System }\end{array}$ & $\begin{array}{l}\text { Social and environment } \\
\text { outcomes }\end{array}$ \\
\hline $\begin{array}{l}\text { Drainage systems } \\
\text { with unitary } \\
\text { networks }\end{array}$ & $\begin{array}{l}\text { Floods; Contamination of soil, } \\
\text { water, and air; Deterioration of } \\
\text { ecosystems; Extinction of } \\
\text { species of flora and fauna; } \\
\text { Proliferation of diseases }\end{array}$ \\
\hline Soil sealing & $\begin{array}{l}\text { Floods; Heat islands; Cutting off } \\
\text { the biophysical matrix; } \\
\text { Decrease in ecosystems; Loss } \\
\text { of goods; Displacement of } \\
\text { animals. }\end{array}$ \\
\hline $\begin{array}{l}\text { Private vehicle } \\
\text { protagonist }\end{array}$ & $\begin{array}{l}\text { Oil spills on the pavement; } \\
\text { Pollution of soil, water, and air; } \\
\text { Noise; Social exclusion; } \\
\text { Sectioning and isolation of the } \\
\text { urban fabric. }\end{array}$ \\
\hline $\begin{array}{l}\text { Lack of rainwater } \\
\text { management }\end{array}$ & $\begin{array}{l}\text { Floods; Contamination of soil, } \\
\text { water, and air; Cutting off } \\
\text { services; Temporary isolation } \\
\text { of communities; Landslides. }\end{array}$ \\
\hline $\begin{array}{l}\text { The } n \\
\text { resid }\end{array}$ & $\begin{array}{l}\text { Contamination of soil, water, } \\
\text { and air. }\end{array}$ \\
\hline $\begin{array}{l}\text { Occupation of } \\
\text { watercourses by } \\
\text { constructions }\end{array}$ & $\begin{array}{l}\text { Reduction in the useful section } \\
\text { for evacuating water and the } \\
\text { capacity of the river } \\
\text { floodplain; Loss of property } \\
\text { and lives; Damage to riparian } \\
\text { forests. }\end{array}$ \\
\hline $\begin{array}{l}\text { Occupation of } \\
\text { coastal inundation } \\
\text { zones }\end{array}$ & $\begin{array}{l}\text { Flood risk; Loss of property } \\
\text { and lives; Damage to coastal } \\
\text { ecosystems }\end{array}$ \\
\hline $\begin{array}{l}\text { Occupation of } \\
\text { wetlands }\end{array}$ & $\begin{array}{l}\text { Flood risk; Infectious disease } \\
\text { risk from pests; Loss of } \\
\text { property and lives; Damage to } \\
\text { wetland ecosystems }\end{array}$ \\
\hline Occupation of slopes & $\begin{array}{l}\text { Landslide risk; Loss of } \\
\text { property and lives }\end{array}$ \\
\hline $\begin{array}{l}\text { Logging of forests } \\
\text { and crops that strip } \\
\text { the soil of its } \\
\text { vegetation cover }\end{array}$ & $\begin{array}{l}\text { Erosion: With consequences } \\
\text { such as soil desertification }\end{array}$ \\
\hline $\begin{array}{l}\text { Canalizations and } \\
\text { diversions of } \\
\text { watercourses }\end{array}$ & Affectation of water bodies \\
\hline $\begin{array}{l}\text { Privatization of the } \\
\text { street }\end{array}$ & $\begin{array}{l}\text { Social exclusion, vandalism, } \\
\text { insecurity }\end{array}$ \\
\hline
\end{tabular}




\begin{tabular}{|l|l|}
\hline $\begin{array}{l}\text { Roads use to form } \\
\text { barriers closing the } \\
\text { train stations }\end{array}$ & $\begin{array}{l}\text { Unapproachability, vandalism, } \\
\text { insecurity }\end{array}$ \\
\hline $\begin{array}{l}\text { The collapse of the } \\
\text { road system }\end{array}$ & $\begin{array}{l}\text { Unapproachability, vandalism, } \\
\text { insecurity }\end{array}$ \\
\hline
\end{tabular}

From the perspective of urban metabolism, it can be affirmed that streets play a significant role in the urban and natural processes and interchanges, therefore, affect the sustainability of the city. Streets redefine the urban geometry, the dynamics of water flows, the soil permeability, and vegetative masses, qualities that modify the response capacity of the built environment to threats.

The traditional urban metabolism methods (ecological footprint analysis, life cycle analysis, and input-output analysis) tend to focus directly on resources, including some environmental effects of resource consumption or flow.

While there have been several studies which have extended these methods to include indicators of social welfare or reshaped the scope of inquiry to provide more detailed environmental or sustainability indicators, it is essential to deepen the study of the consequences generated by the planning and construction of the city on the lifestyles of people and the dynamics of the environment.

The study of the street as a possible facilitator between social and natural processes has not been addressed in depth so far. The street has been studied from two main perspectives, from the ecological point of view and from the social point of view as a public and relational space. However, it is necessary to develop new multi-scale and multi-field methods to study the implications of the street as a large matrix that affects all urban and territorial dynamics. This work seeks to open a window on the study of the street from the urban metabolism. In terms to the contribution to Puerto Rico, this study contributes to the recognition of road infrastructure as a means through which increase the sustainability of the city through an extensive system that is crucial not only for social and environmental well-being but also for dealing with the inherent risks that continuously affect the island.

Based on the arguments exposed above, is raise the following discussion questions:

1. If the streets are the most extensive infrastructure of the built environment, it is possible to increase city sustainability through its reconfiguration?

2. If the streets paved with asphalt are a symbol of the primacy of the automobile as a mean of displacement, but urban sustainability proposes transforming this model, should not be the street one of the main transformation objectives?

3. If the information provided by GIS leads to an accurate recognition of geography and natural processes such as floods and erosion, is it possible to use this information to achieve a better interaction with social processes in the built environment?

4. Recognizing that lifestyles are a significant cause of unsustainability and that the road system is designed to promote it in terms of excessive vehicle use, wasteful use of resources, and production of high rates of pollution, how to rethink the street for a new city model to contribute to a more sustainable lifestyle change?

5. Which planning and participatory methods should be developed to change the biophysical and social flows at different speeds in the urban system?

\section{Conclusions}

The findings of the research are:

1. A lack of empirical evaluation of urban road system policies in San Juan in relationship to natural hazards.

2. Non-recognition of hazards such as floods and landslides, which affect the road system yearround, hampering urban dynamics and putting the population at risk. San Juan' road planning does not take into account the local flood flow patterns, and sub-floodplain hydraulics and related ecology. In this sense, floods are generally grouped into the following types:
a. Riverine flooding
b. Urban drainage
c. Ground failures
d. Fluctuating lake levels
e. Coastal flooding and erosion

FEMA [44] identifies all of these types of floods in Puerto Rico, and all of them affect the road system in different ways. Flood problems are usually solved with patches that provide a short- 
term solution. Until now, there is no plan to restructure the road system from the tools provided by GIS, which integrate the data needed for planning consistent with geographical qualities, and threats.

3. The San Juan road system is conceived as an exclusive means of transport for the vehicle, which reinforces a passive lifestyle.

4. The San Juan road system enhancing the socioeconomic differences, since a significant group of the population, does not have a vehicle and transport on foot; bicycle or public transport.

In this sense, it propose the following recommendations:

- Take advance of the GIS studies that Governmental and Educational Organizations (As the University of Puerto Rico) have about San Juan and all Puerto Rico territory. This information about geographic features is essential to understand the urban metabolism to plan the city in relationship to their environment, and Puerto Rico has the required spatial database. Road design, management, and restoration need to be more carefully tailored to address the full range of ecological processes and terrestrial and aquatic species that may be affected.

- Road systems could embrace different ways of managing the flux of resources throughout the incorporation of SUDS (Sustainable Urban Drainage Systems). In Puerto Rico, SUDS are limited to the building and their close surrounding. Roads must redefine as structures that can retain, spread, and reroute water for common uses recognizing its different qualities.

- The public policies for the road system of San Juan (and Puerto Rico in general) must be aligned with the information provided by GIS. Sustainable reconfiguration of the road system requires the recognition of flooding, runoff, phreatic levels, type, and qualities of soil. Also, the geographical conditions of the territory are not the only issue. It is critical to advance through a sustainable mobility system to avoid car dependence. New towns in the United States could be an excellent example of how to reconfigure the urban sprawl into more connectivity, comprehensive, meaningful, and sustainable structure through the train and subways stations. In this sense, it could take advantage of train and bus stations to generate nodes from which increase urban sustainability through modal transportation systems, and incorporate services and amenities that radiate into the urban structure. Also is endorsed infill the cities with significant activities, spaces, and buildings sloping to increase the opportunities for new jobs, social services, and recreational activities.

- Decarbonized, the road energy in the urban context thoroughly reduces embodied energy and emissions. For that, it's essential to implement strategies as:

- Use of recyclable roads' material construction

- Improving sustainable mobility

- Reduce highways in the urban space

- Eliminate traffic borders;

- And, make more liveable the city by increasing walk paths, and line bikes.

- Is highly recommend the data creation for new or augmenting existing flood and swells hazards, and detailed and specific guidance in what way the road system should be reframed in more sustainable terms. The roads adaptation to make a face to threats or stress, it is essential to track the historical information of hazards.

- The consequences of the natural disasters in San Juan show the need to incorporate energy, food, and water centers along the main streets. Facilitate the provision of essential services and include recurring systems in case of primary system collapse to the road system could help to overcome the hazard situation easily.

The global intervention of the road system has an enormous potential to contribute to the upscaling of climate resilience measures. In this sense, it is also necessary to prioritize the guidelines for the achievement of short, medium, and long-term objectives depending on the levels of risk or stress.

\section{Acknowledgment}

The Dean of Postgraduate Studies and Research of the University of Puerto Rico (FIPI) supported the promotion and dissemination of the results of this research ascribed to the School of Architecture UPR.

\section{References}

[1] L. E. Olsson, T. Gärling, D. Ettema, M. Friman, and S. Fujii, "Happiness and Satisfaction with Work Commute," Soc. Indic. Res., 2013. 
[2] U.S. Department of Commerce, "U.S. Census Bureau QuickFacts: Puerto Rico," 2018. [Online].

Available: www.census.gov/quickfacts/PR. [Accessed: 01-Sep-2019].

[3] B. T. S. O. M. J. D. W, "SUSTAINABLE URBAN STREET DESIGN AND ASSESSMENT AUTHORS," Seattle, Washington, 2007.

[4] J. Gehl and B. Svarre, "Public Space and Public Life," How to Study Public Life, 2013.

[5] R. Wood Johnson, "Active Transportation Making the Link from Transportation to Physical Activity and Obesity," Act. Living Res., 2009.

[6] S. Hall, City, street and citizen: The measure of the ordinary. 2012.

[7] R. C. Deehr and A. Shumann, "Active seattle: Achieving walkability in diverse neighborhoods," Am. J. Prev. Med., 2009.

[8] M. Scholz, "Sustainable drainage systems," Water (Switzerland), 2015.

[9] F. Kazemi, S. Beecham, and J. Gibbs, "Streetscape biodiversity and the role of bioretention swales in an Australian urban environment," Landsc. Urban Plan., 2011.

[10] L. Bertilsson, K. Wiklund, I. de Moura Tebaldi, O. M. Rezende, A. P. Veról, and M. G. Miguez, "Urban flood resilience - A multi-criteria index to integrate flood resilience into urban planning," J. Hydrol., 2019.

[11] A. Wolman, "The Metabolism of Cities," Sci. Am., 1965.

[12] Y. Zhang, "Urban metabolism: A review of research methodologies," Environ. Pollut., 2013.

[13] S. Chen and B. Chen, "Sustainable Urban Metabolism," in Encyclopedia of Environmental Management, 2015.

[14] J. Ravetz, "Integrated assessment for sustainability appraisal in cities and regions," Environmental Impact Assessment Review. 2000.

[15] Z. Guo, D. Hu, F. Zhang, G. Huang, and Q. Xiao, "An integrated material metabolism model for stocks of Urban road system in Beijing, China," Sci. Total Environ., 2014.

[16] S. Moffatt and N. Kohler, "Conceptualizing the built environment as a social-ecological system," Build. Res. Inf., vol. 36, no. 3, pp. 248268, 2008.
[17] J. Breuste, S. Qureshi, and J. Li, "Applied urban ecology for sustainable urban environment," Urban Ecosyst., 2013.

[18] I. L. Stefanovic, Safewarding our Common Future. Rethinking Sustainable Development. New York: State University of New York Press, 2000.

[19] M. Hough, Cities and natural process: A basis for sustainability: Second edition. 2004.

[20] L. W. Mays, Ancient water technologies. 2010.

[21] N. Brooks, J. Hall, and R. Nicholls, "Sea Level Rise: Coastal Impacts and Responses," Civ. Eng., 2006.

[22] E. M. Eid and C. H. Hulsbergen, "Sea level rise and coastal zone management," Clim. Chang. Proc. 2nd World Clim. Conf. Geneva, 1990, 1991.

[23] T. R. Knutson, Tropical cyclones and hurricanes. 2015.

[24] X. Liu, X. Zeng, X. Zou, G. González, C. Wang, and S. Yang, "Litterfall production prior to and during Hurricanes Irma and Maria in four puerto Rican forests," Forests, 2018.

[25] R. Pasch, R.; Penny, A.; Berg, "Hurricane Maria," 2019.

[26] R. P. R. A. Commission, "Reimagina Puerto Rico Economic Development Sector Report," San Juan, PR, 2018.

[27] Urban Regions Now \& Tomorrow. 2017.

[28] P. Ferrao and J. E. Fernandez, "Chapter 3. Intellectual Foundations and Key Insights," in Sustainable Urban Metabolism, 2013.

[29] S. Martinuzzi, W. A. Gould, and O. M. Ramos González, "Land development, land use, and urban sprawl in Puerto Rico integrating remote sensing and population census data," Landsc. Urban Plan., 2007.

[30] Junta de Planificación de Puerto Rico, "Portal Junta de Planificacion de Puerto Rico," 2019. [Online]. Available: https://jp.pr.gov.

[31] M. D. Spalding, A. McIvor, F. H. Tonneijck, S. Tol, and P. van Eijk, "Mangroves for coastal defence: guidelines for coastal managers \& policy makers," 2014.

[32] G. P. Hammond and C. I. Jones, "Embodied energy and carbon in construction materials," Proc. Inst. Civ. Eng. Energy, 2008.

[33] E. Gómez-Baggethun and R. De Groot, "Capital natural y funciones de los ecosistemas: explorando las bases ecológicas de la 
economía."

[34] W. L. Filho and J. de Trincheria Gomez, Rainwater-smart agriculture in arid and semiarid areas: Fostering the use of rainwater for food security, poverty alleviation, landscape restoration and climate resilience. 2017.

[35] S. Narayan et al., "The Value of Coastal Wetlands for Flood Damage Reduction in the Northeastern USA," Sci. Rep., 2017.

[36] F. J. Clubb et al., "COASTAL WETLANDS AND FLOOD DAMAGE REDUCTION Using Risk Industry-based Models to Assess Natural Defenses in the Northeastern USA," J. Geophys. Res. F Earth Surf., 2016.

[37] A. E. Sutton-Grier and P. A. Sandifer, "Conservation of Wetlands and Other Coastal Ecosystems: a Commentary on their Value to Protect Biodiversity, Reduce Disaster Impacts, and Promote Human Health and Well-Being," Wetlands, 2018.

[38] "Programa del Estuario de la Bahía de San Juan - Ciudad de las aguas - City of the waters." [Online]. Available: web.estuario.org/. [Accessed: 19-Sep-2019].

[39] N. Chrysoulakis, E. Castro, E. Moors, and , A, CCCPR. . Puerto Rico Climate Change Council. 2014.

[40] I. Center for Climate Strategies, "Puerto Rico Greenhouse Gases Baseline Report," San Juan, 2014.

[41] S. F. Balica, N. G. Wright, and F. van der Meulen, "A flood vulnerability index for coastal cities and its use in assessing climate change impacts," Nat. Hazards, 2012.

[42] M. Fenster and R. Dolan, "Assessing the Impact of Tidal Inlets on Adjacent Barrier Island Shorelines," J. Coast. Res., 1996.

[43] S. Martinuzzi, W. A. Gould, A. E. Lugo, and E. Medina, "Conversion and recovery of Puerto Rican mangroves: 200 years of change," For. Ecol. Manage., 2009.

[44] Fema, "No Title," 2017. [Online]. Available: https://hazardsfema.maps.arcgis.com/apps/webappviewer/ index.html?id=8b0adb51996444d4879338b 5529aa9cd. 